\title{
Research on the Improvement Model of Physical Education Model Based on Humanistic Sports Spirit in College Sports
}

\author{
Hui Du \\ Department of Physical Education, Wuhan University of Science and Technology, Wuhan 430081, China
}

Keywords: improvement model; Physical Education model; humanistic sports spirit; College Sports

\begin{abstract}
The cultivation of humanistic spirit is of great significance to the overall development of students. The integration of physical education and humanistic spirit in colleges and universities meets the needs of social development, meets the needs of physical education reform in colleges and universities, and also meets the needs of students' talents. In order to promote the integration of physical education and humanistic spirit, it is necessary to change and improve the concept, content of teaching, humanistic qualities of physical education teachers, and humanistic environment of physical education.
\end{abstract}

\section{Introduction}

With the improvement of Chinese economic development level and social progress, people are more willing to spend more time and energy on physical exercise for an increasingly healthy lifestyle. This change in thinking is due, on the one hand, to the ideological ideology of people. Progress, on the other hand, is due to the enormous pressure of existence that has caused a very bad influence on people's physical fitness. People must strengthen their physical fitness through physical exercise. Physical education in colleges and universities is an important part of all people's physical education, and it is also increasingly focused on by all walks of life. Because the level of physical education in colleges and universities directly relates to the physical conditions of college students, and then affect the size of the backbone of the next generation to build the motherland. In the physical education of modern colleges and universities, on the one hand, more and more attention is paid to the scientific nature of physical education. Scientific physical education can reduce the risk of sports injuries. On the other hand, physical education in colleges and universities also pays more attention to the humanities of education. The spirit of humanistic sports gradually penetrates modern sports teaching and gradually becomes the core part, guiding the normal conduct of teaching work and promoting the improvement of teaching standards. In the new era, the spirit of humanistic sports also has a broader connotation, and is a symbol of the national spirit listed on a certain level. In the process of physical education in colleges and universities, it is necessary to fully respect the university student's dominant position, take people as the basis, teach students in accordance with their aptitudes, design the physical education program of the undergraduates scientifically and rationally, combine the physical condition of the undergraduates, and set up physical education items scientifically and reasonably to increase the physical education teaching process. The humanistic spirit requires that physical education in colleges and universities can improve the physical quality of college students, master certain sports skills, develop good physical exercise habits in learning and living, and promote physical and mental health.

\section{The Connotation of Humanistic Sports Spirit}

The so-called humanistic sports spirit refers to the combination of humanistic spirit and physical education in two different fields. It is a scientific product formed by the mutual fusion of sports and humanistic spirits. It has a great role in promoting the development of the two fields. The core composition of the humanistic sports spirit is the two parts of sports and humanities. The performance of the humanistic sports spirit in reality means that in the process of sports, training 
and sports competition, people-oriented, seeking truth from facts, and fair treatment of all events in sports activities. In the new era, the spirit of sports humanities has also given new meanings to physical education in colleges and universities. On the one hand, in the physical education process, students should be the center of the student, and students should be the core to promote the healthy development of students. On the other hand, in the process of physical education in colleges and universities, students' health should be the primary The premise, on this basis, formulate a scientific plan to improve the physical quality of college students, and in the teaching process, let students experience the care of the humanistic spirit, feel the connotation of the humanistic spirit, and promote the college students to form a noble moral sentiment and a good psychological quality. .

\section{The Characteristics of Improved Physical Education Model of College Sports Teaching}

The phenomenon of public sports in any college is the result of students' direct participation in the purposeful behavior. The characteristics of students' sports behavior constitute the forming elements of the public sports humanistic spirit training model.

The natural transformation of physical education for college students reflects not only the morphological structure, but also more importantly the improvement of physical activity and the enhancement of basic activities. Physiological structure is the material basis of physical activity and is the basic factor that constitutes a person's ability to exercise. The characteristics of a person's physiological structure largely determine whether a person can engage in competitive sports and what kind of sports they perform and what they can achieve. Different sports programs have their own special requirements for students' body shape, function and quality, and they have different focuses. This is the result of natural selection of various sports in the long-term development process. It is also a result of extensive observations and experimental studies by experts. TSports behavior is constrained to a certain extent by the physiological mechanism based on innate genetics. However, as a positive influence method it will, to a certain extent, improve the physiology of students and make the physical quality develop well.

In the whole process of engaging in sports, students not only have explicit visible sports activities, but also are full of implicit needs, motivations, values, aesthetic interests, interests, emotions and other psychological activities. The diversity and individual differences of students' sports behavior are not only restricted by their physiological mechanisms and environmental mechanisms, but also influenced more by individual psychological mechanisms. Psychological mechanism plays an important intermediary role in the process of individual sports behavior. The influence of physiological factors and environmental factors on students' sports behaviors mainly plays a role through this intermediary.

Sports behavior is motivated, initiative, and interactive. There are social and psychological interactions such as imitation, infection and herd in the process of sports activities. The fair competition, coordinated cooperation, strict rules, hard work, and survival of the fittest in sports activities provide a clear reference for fair competition, law-abiding, and hard-working wealth advocated by commodity economy and society. Therefore, sports behavior is a kind of social behavior with distinctive social characteristics. It is precisely because of the characteristics of social behavior in sports behavior, so it can exert its social functions through sports behavior activities. First, physical activity activities can effectively promote the socialization of students. By participating in sports activities, students can not only learn the basic skills and skills needed for social life, but also can gradually establish the moral awareness and normative awareness necessary for social life in the process of adhering to the rules of the activities. The modern society needs the spirit of competition, enterprise, and hard work. It can also foster good qualities such as mutual respect, unity and cooperation, love of the collective, and maintenance of justice. Second, sports activities with its unique interpersonal interaction function will undoubtedly become an effective means and method for students to adjust their body and mind, adjust their rhythm, and adjust their lives. In addition, the sports activities also have special functions of non-verbal communication, which enables students to communicate and resonate emotionally through demonstration, imitation, and comprehension of physical communication. 
Sports behavior is a kind of symbolic behavior. It is a kind of cultural behavior that carries certain information. In addition to the external aesthetic beauty, human beauty, and clothing beauty that are highly admirable, there is also the vigor of the behavioral subject. Through a variety of sports activities, students communicate in a variety of cultural information, both intentionally and unintentionally. The combination of sports competition and culture makes the original pure sports competition adds a deep cultural connotation. The physical culture and competitive culture created by human beings have greatly enriched the human cultural treasures. With its unique charm, it has attracted more and more students to this cultural activity. The generation and development of sports behavior is a process of cultural creation and dissemination that mirrors the light of human wisdom, and promotes the progress and development of human culture.

\section{Analysis of the Participation Path of Humanistic Spirit in Physical Education in Colleges and Universities}

People have natural needs, social needs, and spiritual needs. Natural needs and social needs are only temporary, relative, limited desire points. The generation of spiritual life is the root of human beings. With the focus of physical education in colleges and universities shifting to "health first", in the ordinary teaching, we must establish a clear teaching idea that is for all students, grasp the laws of education, focus on the idea of life-long sports, and change the physical fitness to the harmonious development of the body and mind. The transition from heavy technology to the development of physical education ability, from general education to teaching students in accordance with their aptitude, highlights the joyful physical and mental function of sports and gives students a successful experience and motivation. To this end, physical education in colleges and universities should pay attention to improving the humanistic spirit of sports. School sports must establish an education concept of "service for quality education", pay attention to the overall development of students' physique and mind, expand the boundaries of physical education, and cultivate students' sensitive sentiments and profound experience. Physical education in colleges and universities cannot be confined to the educational benefits of "enhancing physical fitness, improving health, and mastering knowledge and skills" in the immediate future. We must also look to the future, pay attention to the integration of school sports and society and families, and pay attention to the connection between school sports and the social environment and the natural environment. Only by uniting science and humanities, knowledge and character, rationality and irrationality, and learning and living can we cultivate people with a harmonious development of both body and mind.

In terms of teaching content, physical education curriculum should focus on embodying the characteristics of the era and humanistic characteristics, linking the content of the curriculum with student life, and cultivating the students' humanistic spirit in teaching activities. Compared with other disciplines, physical education teaching is a special teaching process, which inherently contains the connotation and value of the humanities. It is necessary to educate students through humanistic education through physical education. First, the content of physical education courses should be rich. Physical education classes should not be entirely the content of competitive sports such as track and field and ball games, nor should they be uniform and uniform teaching content. Instead, they should determine teaching content according to the actual situation of students under the guidance of physical education objectives in colleges and universities to increase the number of courses. The content is selective to meet the diverse needs of students. In the selection of sports events, we must balance sports skills, health, and humanistic spirit. Second, the teaching content should reflect the humanistic spirit. The contents of physical education should be reformed and improved, and some teaching contents with humanistic spirit should be selected. Through learning, students can not only acquire knowledge and skills, but also get "real, good, and beautiful" sentiment.

Any education must be implemented by teachers. Physical education is no exception. The integration of humanistic spirit in physical education in colleges and universities is the key to physical education teachers. In the teaching practice, it is found that the integration of physical education and humanistic spirit depends on the improvement of the humanistic quality of physical 
education teachers. First, teachers should establish a student-centered education philosophy. In physical education teaching, whether it is the teaching process, teaching content, or teaching methods, students should be the center of the matter. Starting from reality, students should be concerned about their acceptance level and physical and mental experience. In the setting of curriculum objectives and the selection of curriculum content, teachers should consider the differences among students, give full respect to each student, focus on the overall development of the students, and take care of the students' different needs and interests. Second, teachers must have the spirit of service. In the World Trade Organization, education is seen as a service. We must also gradually establish a concept in which students are consumers of higher education and teachers are service workers in higher education. In this new type of teacher-student relationship, teachers and students are equal in personality and are the subject of teaching. P.E. teachers should also change the traditional view of teachers and students, and re-position the role, that is, serve the sports teaching in the spirit of service.

\section{Conclusion}

In the physical education of ordinary colleges and universities in the new century, the sports skills are oars. The humanistic spirit of sports is the rudder. It is necessary to use sports humanistic spirit to coordinate the relationship between people and sports skills and people. In physical education teaching, it is necessary to strengthen students' spiritual and spiritual cultivation in sports so that scientific, healthy, progressive, and advanced sports humanistic spirits and sports skills complement and perfect each other, so that students develop good moral character, mentality, interests, and hobbies. And learn to be a human. Therefore, it is one of the important tasks of physical education teaching in colleges and universities in China to seek a spiritual paradise for college sports teaching in the new century, to reshape beliefs and values in the soul, and to build the sports humanistic spirit in the new century.

\section{References}

[1] Song Jixin. On the concept of erudite scholarship and educating people to win the bid [J]. Journal of Jilin Institute of Physical Education, 2003, (1)

[2] Shao Changsheng. On the humanistic spirit should become the goal of physical education [J]. Journal of Jilin Institute of Physical Education, 2003, (3)

[3] Ouyang Liuqing. Sports Humanistic Spirit and Sports Modernization [J]. Journal of Shanghai Institute of Physical Education, 2003, (4)

[4] Yang Deguang. Humanistic education is the education of man [J]. Higher Education, 2003, (6) 